chromatic photographs of the corona in the light of the corona line $\left(\lambda_{53} 3_{3}\right)$. The observing station is some 3000 feet above sea-level.

The Perseid Shower of Meteors.-His watches for meteors on August Io and II having disclosed but very meagre displays, $\mathrm{Mr}$. Denning is led to believe that something must have intervened to bring about a very marked decline in the splendour of this noted shower. In a table, appearing in No. $45^{2}$ of The Observatory, he shows how very few Perseids are now seen as compared with a decade ago. In Igor, during two watches of $6 \frac{3}{4}$ hours in all, he saw I04 Perseids, in 1907 (6 hours) he saw Ior, and in 1909 ( 4 hours) 79. Last year only three Perseids were seen in $2 \frac{1}{2}$ hours, while this year only fourteen rewarded his two watches of $2 \frac{1}{4}$ and $1 \frac{1}{2}$ hours respectively. The conditions were not good, but, when compared with the 252 Perseids seen in 4 hours in 1874 , and 285 in 5 hours in 1877 , it would appear that something more than poor observing conditions must be held accountable for the poverty of recent displays.

The Solar Constant and Climatic Changes.-In a third paper on climate and crops, published in the Bulletin of the American Geographical Society for August, Mr. Henryk Arctowski compares the temperature records made at Arequipa during the period r900-10 with the Washington values for the solar constant, and finds evidence of agreement between them; he also shows that Arequipa is not exceptional. His results indicate that a departure of $I^{\circ} \mathrm{F}$. in the monthly mean observed at Arequipa is due to a departure, of about $0^{\circ} 015$, of the solar constant from its normal value. If this be true, a comparatively small, but permanent, lowering of the constant would account for such climatical conditions as existed during the Pleistocene Ice age. Mr. Arctowski also finds that the oscillations of temperature found in his data correspond to those of atmospheric pressure to which Lockyer assigned a mean period of 3.8 years.

The Leeds Aştronomical Society.-The Journal and Transactions (No. 19) of this society for IgI I contains reports of a number of papers read before the society. Among others, there is an interesting discussion of the mutual eclipses of the satellites of Jupiter, by Mr. Whitmell, a paper dealing with suitable observations for amateur astronomers, by $\mathrm{Mr}$. Ellison Hawks, and a discussion of the structure and sidereal significance of nebulæ by the Rev. Ivo Gregg. The membership now totals seventy-five, and the average attendance at meetings is fourteen.

The Period and Orbit of $\alpha$ Persei.-From measures of a number of radial-velocity spectrograms, secured at the Potsdam Observatory between rooo and 1908 , Dr. A. Hnatek has derived an orbit for the spectroscopic binary a Persei, which he publishes in No. 4599 of the Astronomische Nachrichten. The variability of the velocity of this star, although small, now appears to be established, and Dr. Hnatek's results indicate a very short period of 40938 days. The radial-velocity of the. system is $-3.43 \mathrm{~km}$., the eccentricity of the orbit 047 , and the length of the semi-major axis of the projected orbit $46,000 \mathrm{~km}$.

\section{NEW RULES FOR LIFE-SAVING APPLIANCES IN BRITISH SHIPS.}

$\mathrm{M}$. BUXTON has lost no time in considering and giving effect to the recommendations made by Lord Mersey and his colleagues, as well as the report of the Advisory Committee. The character of these recommendations and of that report has been described NO. 2238, voL. 9o] fully in previous issues (see Nature, August 8 and 29 ); it will suffice, therefore, briefly to indicate the most important points in the Parliamentary Paper (Cd. 6402) issued a few days ago, in which the new rules made by the Board of Trade are contained. Those rules will not have statutory effect until they have lain on the table of the House of Commons for forty days, and it is not proposed that they shall come into effect until January I, I9r3. It is practically certain that when Parliament reassembles the rules will be criticised, and it is possible that they may be amended in some respects as the result of that criticism.

Although the rules previously issued have been accepted without serious challenge, the circumstances of the present revision and the drastic nature of some of the new regulations may cause a departure from precedent. Mr. Buxton has recognised the special conditions of the revision of the rules, and has wisely prefaced them by an explanatory memorandum which is both comprehensive and clearly expressed. His memorandum gives the history of the steps which have been taken by the President of the Board of Trade to deduce all possible lessons from the loss of the Titanic in order to secure greater safety in future for life and property at sea.

It is also, in effect, an attempt to justify the rules themselves in those features wherein the report of the Advisory Committee has been departed from. That report has been dealt with somewhat harshly by critics, who are disposed to think that shipowners serving on the committee have been unduly influenced by consideration of their class-interests. There is no real foundation for such an opinion, and $\mathrm{Mr}$. Buxton marks his dissent therefrom by stating that, although he has been unable to adopt the conclusions of the committee on some material points, its report has been of very great value, and that he desires to express a high appreciation of the time "and pains expended by the members of the committee and of its various subcommittees on the important questions referred to them." Nothing but prejudice could lead to the conclusion that the shipowners and shipbuilders, who have given gratuitous and unstinting service on these inquiries, would have allowed personal considerations to weigh with them. On the contrary, it is clear that no classes of the community can have a greater interest in securing safety at sea, and certainly no other persons have done so much during the last twentyfive years to increase that safety.

The main point of difference between the Advisory Committee and the new official rules is to be found in the provision that foreign-going passenger and emigrant ships are in future to have sufficient lifeboat accommodation for all on board; whereas the committee recommended that lifeboats should be supplemented by rafts, collapsible boats, \&c. It is intended further to consider the extent, if any, to which liferafts may be used when the report of the Davits and Boats Committee-which is about to commence its labours-has been received. Collapsible boats are not to be included in future estimates of life-saving accommodation, although they may be continued in use in existing vessels for a certain period-not specified. On this point there will be debate, and there is reason for difference of opinion. Whatever the final decision may be, it should be noted that there is now universal agreement that in all cases, even in the best subdivided foreign-going ships, every soul on board shall have a chance of keeping afloat in boats, rafts, or other appliances, in case a ship founders through collision, grounding, or other accident. For ships in the home trade less stringent provisions are insisted upon in respect of life-saving accommodation, and this course 
is reasonable having regard to the restricted range of their employment and the greater chance of external help in case of accident.

What remains to be demonstrated-and the task will not be an easy one-is whether the large number of lifeboats now thought to be essential can possibly be so carried as to be loaded and got into the water safely within a reasonable time after an accident has taken place-say within half an hour or an hour. Judging by the Titanic--in which case all the circumstances were most favourable to the loading and lowering of boats-radical changes will be required in the installation of lifeboats and in the means of lowering them, if this essential condition is to be fulfilled. All that need be added is that whatever may be the number of lifeboats carried, and however efficient may be the details of the arrangements for lowering these boats, it is obviously of primary importance to secure efficient watertight subdivision in passenger ships, so as to minimise the risk of foundering and to lengthen out the time which ships will remain afloat in cases of accidents so serious as to involve their final sinkage. On this matter another committee is still at work, and no action can be taken by the Board of Trade until its report has been presented.

\section{ATMOSPHERIC PRESSURE AND TEMPERATURE.}

IN Aus dem Archiv der deutschen Seewarte, I9II, No. 4, W. Brockmöller discusses the geographical distribution of the monthly range of oscillation of the barometer. So far as the southern hemisphere is concerned, the question was thoroughly investigated by Dr. W. J. S. Lockyer in a recent publication of the Solar Physics Committee, but Herr Brockmöller's treatment of the subject covers a wider area, and is based on a different definition of the "range." He takes as the measure of this the mean value of the difference between the highest and lowest barometer readings for each month, and deals with a selection of stations, about 300 in all. After correcting the values for the periodic semi-diurnal variation, and for height above sea-level in the case of a few high-level stations, he plots the values for winter (DecemberFebruary), and for summer (June-August), and obtains two very interesting charts, showing the isobarometric lines, or lines of equal range. For the northern hemisphere he obtains also normals for different latitudes, and draws the isanomalies, or lines of equal departure from normal. The range is least, 3 or $4 \mathrm{~mm}$., in the equatorial region, and greatest near the arctic circle, apparently diminishing again towards the pole. The outstanding features are the maxima, in both seasons, near Iceland and the Aleutian Islands, the regions of the "permanent cyclones." The maxima are naturally much less intense in summer than in winter. Perhaps even more remarkable is the large value of the anomaly on the east coast of North America, where it is greater than at any other place. The effect is possibly due to the proximity of the division between the Labrador current and the warmer water of the North Atlantic, but it is deserving of further investigation.

In the same journal, No. 5, Prof. Köppen and Dr. Wendt discuss the vertical distribution of temperature over Hamburg between the earth's surface and a height of $3000 \mathrm{~m}$. The records obtained in nearly x200 ascents of kites and balloons during the years I904-9 have been analysed very thoroughly, and a new departure has been made in the special treatment of so-called inversions of temperature-gradient. The authors find that such inversions occur in 69 out of NO. 2238, vOL. go] every roo ascents, the temperature remaining constant or increasing with altitude. Inversions are most frequent in autumn and winter, and in December they are found in nearly every ascent. At all seasons they occur most frequently with southerly winds. Inversions in which the increase of temperature exceeds $3^{\circ} \mathrm{C}$. are almost invariably accompanied by a decrease in the relative humidity except for those which occur in the layer between the earth's surface and a height of $500 \mathrm{~m}$. At all seasons the sky is more frequently cloudy than clear on the occasions when inversions are recorded, but in spring and autumn the number of cases of clear sky is large. The clouds were found usually to have their lower surfaces below $500 \mathrm{~m}$., except in those cases in which inversions occurred below $500 \mathrm{~m}$. Another section of the paper deals with the dependence of temperature-gradient on wind direction. Near the surface the gradient is greatest with $\mathrm{N}$. winds, above $500 \mathrm{~m}$. with W. winds, and above $1000 \mathrm{~m}$. with S.W. winds. As the wind usually veers with increasing height, it seems probable that the actual direction of the current for maximum gradient in the layer considered will be northerly at all heights.

\section{PLANKTON INVESTIGATIONS.}

I $N$ the Bulletin Trimestriel, I9II, the second part of the "Résumé des Observations" continues the summary of the plankton investigations carried out under the international programme in the north-east Atlantic and north-west European waters during the years rgo2-8. The subjects here dealt with are the Copepoda, Tunicata, Ostracoda, Chætognatha, Amphipoda, Rotatoria, and Ceratium. With the vast amount of material collected in course of the investigations external records are incorporated in a discussion of the seasonal occurrence and distribution of the species considered, and the hydrographic conditions associated in each case with such. The annual and seasonal distribution and intensity of many of the more important species are shown in a number of separate charts. From an economic point of view, attention is directed to the importance of many of the Copepoda and Amphipoda as constituting in a large measure the food supply of Clupeoids, Gadidæ, the mackerel, and other marketable fishes.

As bearing directly on questions of physical oceanography, Salpa and Doliolum among the Tunicata afford important examples of warm-water species drifted as annual visitors to our coasts by the agency of the Gulf Stream. Similarly, several species of Ceratium show a distribution largely increased by immigration through the Faroe-Shetland Channel into the North and Norwegian Seas and beyond. Some of the latter species have a second sphere of distribution in the West Atlantic, from Florida to Newfoundland, and the author of this section, who has traced some of them sparingly at wide intervals across the Atlantic to the American coast, is of opinion that the two spheres of distribution are indeed in communication by virtue of the east-going oceanic movement. Conversely, among the brackish-water Rotatoria, species find their extension during the summer months from the Gulfs of Finland and Bothnia over the Baltic and outwards, mainly dependent on the periodic surface outflow of low-salinity water in this region. For the further elucidation of these complex problems, more exact information is required concerning some of the more critical species, and the need is felt, in particular, for a greater extension of the area of investigations to the westward and south-westward of Ireland. 